䖵 


\section{Series Editor}

Prof. Dr. Michael J. Parnham

PLIVA

Research Institute

Prilaz baruna Filipovica 25

10000 Zagreb

Croatia 


\title{
Medicinal Fatty Acids in Inflammation
}

\author{
Joel M. Kremer
}

Editor

Springer Basel AG 
Editor

Prof. Dr. Joel M. Kremer

Professor of Medicine

Head, Division of Rheumatology

Albany Medical College

Albany, NY 12208

USA

A CIP catalogue record for this book is available from the Library of Congress, Washington D.C., USA

Deutsche Bibliothek Cataloging-in-Publication Data

Medicinal fatty acids in inflammation / ed. by J. Kremer ... Springer Basel AG 1998

(Progress in inflammation research)

ISBN 978-3-0348-9788-4 ISBN 978-3-0348-8825-7 (eBook)

DOI 10.1007/978-3-0348-8825-7

The publisher and editor can give no guarantee for the information on drug dosage and administration contained in this publication. The respective user must check its accuracy by consulting other sources of reference in each individual case.

The use of registered names, trademarks etc. in this publication, even if not identified as such, does not imply that they are exempt from the relevant protective laws and regulations or free for general use.

This work is subject to copyright. All rights are reserved, whether the whole or part of the material is concerned, specifically the rights of translation, reprinting, re-use of illustrations, recitation, broadcasting, reproduction on microfilms or in other ways, and storage in data banks. For any kind of use, permission of the copyright owner must be obtained.

\section{(C) 1998 Springer Basel AG}

Originally published by Birkhäuser Verlag in 1998

Softcover reprint of the hardcover 1st edition 1998

Printed on acid-free paper produced from chlorine-free pulp. TCF $\infty$

Cover design: Markus Etterich, Basel

ISBN 978-3-0348-9788-4

987654321 


\section{Contents}

List of contributors.......................................... vii

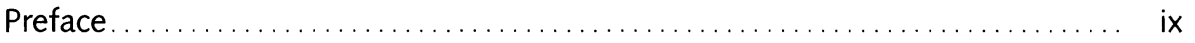

Philip C. Calder

$n-3$ Polyunsaturated fatty acids and mononuclear phagocyte function ...

Robert B. Zurier

Gammalinolenic acid treatment of rheumatoid arthritis

Vincent A. Ziboh

The role of $n-3$ fatty acids in psoriasis.

David F. Horrobin

$n-6$ Fatty acids and atopic eczema

David F. Horrobin

$n-6$ Fatty acids and nervous system disorders

Gabriel Fernandes

$n-3$ Fatty acids on autoimmune disease and apoptosis

Andrea Belluzzi and Federico Miglio

$n-3$ Fatty acids in the treatment of Crohn's disease

John B. Rodgers

$n-3$ Fatty acids in the treatment of ulcerative colitis

Piet P. Geusens

$n-3$ Fatty acids in the treatment of rheumatoid arthritis. 
Joseph P. Grande and James V. Donadio

$n-3$ Polyunsaturated fatty acids in the treatment of patients with

IgA nephropathy

Subject index 


\section{List of contributors}

Andrea Belluzzi, Department of Emergency Medicine, S. Orsola Hospital, Via Massarenti, 9, I-40138 Bologna, Italy; fax: ++3951 399914

Philip C. Calder, Institute of Human Nutrition, University of Southampton, Bassett Crescent East, Southampton SO16 7PX, UK

James V. Donadio, Division of Nephrology, Mayo Clinic, 200 First Street SW, Rochester, MN 55905, USA; e-mail: donadio.james@mayo.edu

Piet P. Geusens, Clinical Research Center for Bone and Joint Diseases, Dr L. Willems-Instituut, Limburgs Universitair Centrum, B-3590 Diepenbeek, Belgium; e-mail: geusens@tornado.be

Joseph P. Grande, Division of Anatomic Pathology, Mayo Clinic, 200 First Street SW, Rochester, MN 55905, USA; e-mail: grande.joseph@mayo.edu

David F. Horrobin, Laxdale Research, King's Park House, Laurelhill Business Park, Stirling, Scotland FK7 9JQ

Federico Miglio, Department of Emergency Medicine, S. Orsola Hospital, Via Massarenti, 9, I-40138 Bologna, Italy; fax: ++39 51399914

John B. Rodgers, Albany Medical College, A-48, Department of Medicine, 47 New Scotland Avenue, Albany, NY 12208, USA

Vincent A. Ziboh, Department of Dermatology, TB 192, School of Medicine, University of California, Davis, CA 95616, USA

Robert B. Zurier, University of Massachusetts Medical Center, 55 Lake Avenue North, Worcester, MA 01655, USA; e-mail: robert.zurier@banyan.ummed.edu 


\section{Preface}

This volume of Progress in Inflammation Research is a unique compilation of work performed by a wide spectrum of investigators from different medical disciplines. It is fascinating that dietary alterations of fatty acid intake can result in a range of salutory changes in a great variety of medical conditions. Most of the good scientific work which has led to these observations has been performed over just the last two decades. This is of course not a very long time in the context of the history of the human species. Recently performed analysis of fat intake from paleolithic times has indicated that our hunter-gatherer ancestors consumed as much cholesterol as modern Western man, but strikingly less saturated fatty acid and more polyunsaturates, including $n-3$ fatty acids. Wild game has the terrestrial source of $n-3$ incorporated in its fat since browsing animals derive 18:3n-3 (alpha-linolenic acid) naturally from leafy plants.

There is, however, little opportunity for modern Western man to get $n-3$ fatty acids from the diet if one does not consume fish. Modern agribusiness provides animal feeds high in $n-6$ fatty acids, mostly derived from linoleic acid $(18: 2 n-6)$ in corn feed. Therefore, grazing animals have no access to alternative fatty acids in either feed or grasses, the latter containing little or none of these potentially beneficial highly polyunsaturated fatty acids. We have, as a species, passed the overwhelming majority of our time evolving with foods containing $n$-3 fatty acids only to have them removed in the last 200 years. Some have speculated that the prevalence of inflammatory diseases has increased during this same time interval as a direct result of the change in our dietary intake of fatty acids. This is a controversial premise which is difficult, if not impossible, to prove. The evidence is circumstantial at best. There are certainly many other dietary and environmental changes which have occurred in the Western World over the same time interval.

However, only the lipid content of the diet is reflected in the basic structure of the cell. The phospholipid component of the lipid bilayer of the plasma membrane is determined by dietary fatty acid intake. Thus diets rich in $n-3$ or $n-6$ fatty acids including gammalinoleic acid (GLA) will result in the incorporation of these fatty acids into the plasma membrane. There they serve as alternative substrates to arichi- 
donate for oxidative pathways leading to eicosanoid production. This is reviewed in several chapters in this volume. In addition, a host of other cellular changes may occur which result in modifications of immune function. The emerging evidence on the mechanisms of these dietarily induced alterations is found elsewhere in this volume.

We have as a species rounded a scientific corner with this new information. Inflammatory diseases must be added to atherosclerosis and malignancy in an expanding listing of medical conditions which can unequivocally be affected by diet. These advances are the natural outgrowth of both a worldwide heightened interest and awareness of nutrition and the increasingly sophisticated scientific techniques, including those of molecular biology, which have been utilized to explore the mechanism of action of dietary alterations in fatty acids.

As in most new developments which lead to a fundamental alteration in the way people view their world, universal acceptance is often slow to come forth. It is sometimes easier to be a skeptic in the face of new information which alters our view of the natural order of things than to give ourselves over to a new world view. Nevertheless, with the passage of time, the validity of new ideas and observations become accepted with resultant behavioral modifications. This will surely be the case with the description of the effects of fatty acids on inflammation which are found in this volume.

Joel M. Kremer

March, 1998

Albany, USA 